\title{
ANALYSIS OF DYNAMIC LOADS ON THE CARS OF A HIGH-SPEED MOTOR- CAR TRAIN WITH A PASSIVE SAFETY SYSTEM IN ITS COLLISION WITH A FREIGHT CAR
}

\author{
Institute of Technical M echanics \\ of the National Academy of Sciences of U kraine and the State Space Agency of U kraine, \\ 15 Leshko-Popel St., Dnipro 49005, U kraine; e-mail: sobmb@i.ua
}

\begin{abstract}
The performance characteristics of the cars of a modern home high-speed motor-car train must meet Ukrainian State Standards DSTU EN 12663 and DSTU EN 15227 now in force in Ukraine, which regulate its crashworthiness and passive safety in emergency collisions. An integral part of new cars must be passive safety systems (PSSs) with energy-absorbing devices (EADs), which save the lives of the pasengers and the train crew and reduce car damage in a collision with an obstacle. The aim of this paper is to evaluate dynamic loads on the cars of PSS-equipeed motor-car train in its collision with a freight car according to Scenario 2 of DSTU EN 15227. The scientific novelty of the paper is a mathematical model for the study of a collision of a motor-car train with a freight car based on the authors' model of a collision of identical motor-car trains (Scenario 1 of DSTU EN 15227) with account for the force characteristic of head car - freight car interaction in an emergency. The proposed mathematical model allows one to obtain the average values of the car accelerations and plastic deformations to compare them with their admissible values according to DSTU EN 15227. The paper presents the results of a study of dynamic loads on the cars of a PSS-equipped motor-car train in its collision at $36 \mathrm{~km} / \mathrm{h}$ with a $80 \mathrm{t}$ freight car for a reference train with a 80 head car and four intermediate cars of mass $50 \mathrm{t}$, which is the mass of the majority of cars on the $1,435 \mathrm{~mm}$ European railways, and $64 \mathrm{t}$, which is the typical mass of inremediate cars used in the $1,520 \mathrm{~mm}$ Ukrainian railways. The following protective devices developed at the Institute of Technical mechanics of the National Academy of Sciences of Ukraine and the State Space Agenccy of Ukraine are proposed for passive protection: EAD 1 devices of energy capacity $0.95 \mathrm{MJ}$ to be mounted at the coupler level at the head car front end, EAD 2 devices of energy capacity $0.25 \mathrm{MJ}$ and EAD 3 devices of energy capacity 0.3 MJ to be mouned at the coupler level at the head car rear end and at the ends of passenger cars of mass $50 \mathrm{t}$ and $64 \mathrm{t}$, respectively, and EAD UL upper-level energy-absorbing devices of energy capacity of $0.12 \mathrm{MJ}$ to be mounted at the head car front end under the window. It is shown that by the criteria of DSTU EN 15227 for a train with $50 \mathrm{t}$ intermediate cars it is advisable to use the passive protection according to Scenario 1 (the front end of the head car is equipped wuth two EAD 1 and two EAD UL devices, its rear end is equipped with two EAD 2 devices, and the intermediate cars are equipeed with two EAD 2 devices at the front and at the rear), while for a train with $64 \mathrm{t}$ intermediate cars it is advisable to use the passive protection according to Scebario 2 (the front end of the head car is equipped wuth two EAD 1 and two EAD UL devices, its rear end is equipped with two EAD 3 devices, and the intermediate cars are equipeed with two EAD 3 devices at the front and at the rear). The proposed mathematical model and the results obtained may be used in designing head and intermediate cars for a home motor-car passenger train in accordance with the DSTU EN 15227 requirements.
\end{abstract}

Keywords emergency collision, motor-car train, freight car, head car, passive safety system, energyabsorbing devices.

1. Ukrainian State Standard DSTU EN 12663-1:2018 (EN 12663-1:2010 + A1:2014, IDT). Railway transport. Structural requirements for railway vehicle bodies. Part 1. Locomotives and passenger cars (and an alternative method for freight cars). 2018. 18 pp. (in Ukrainian).

2. Ukrainian State Standard DSTU EN 15227:2015 (EN 15227:2008+A1:2010, IDT). Railway transport. Crashworthiness requirements for railway vehicle bodies. 2016. 37 pp. (in Ukrainian).

3. European Standard EN 12663-1: 2010. Railway applications - Structural requirements of railway vehicle bodies. Brussels, 2010. 18 pp.

4. European Standard EN 15227: 2008. Railway applications - Crashworthiness requirements for railway vehicle bodies. Brussels, 2008. $37 \mathrm{pp}$.

5. Sobolevska M. B.,Naumenko N. Yu., Horobets D. V. Mathematical simulation of dynamic loads on a head car with a passive safety system in a collision of identical motor-car trains. Teh. Meh. 2020. No. 2. Pp. 66-79. (in Ukrainian).

https://doi.org/10.15407/itm2020.02.066 
6. Roberts J., Fraikin B., Leveque D. Development and validation of a regional train platform to the requirements of EN 15227. Proc. of the 7th Int. Symp. 20-21.11.2008 on Passive Safety of Rail Vehicles. Innovation in Passive Safety and Interior Design (Berlin: IFV Bahntechnik e.V.). 2008. V. 17. Pp. 237-248.

7. Series 422 electric train. Zhelesnye Dorigi Mira. 2010. No. 5. Pp. 37-49. (in Russian).

8. Railway vehicle production in the East-European countries. Zhelesnye Dorigi Mira. 2019. No. 3. Pp. 61-65. (in Russian).

9. Interstate Standard GOST 32410-2013. Emergency crash-systems for railway passenger vehicles. Technical requirements and inspection methods. Moscow: Standartinform, 2014. 11 pp. (in Russian)

10. Nazarov O. N. Technical features of the Velaro Rus high-speed electric train. Tekhnika Zheleznykh Dorog. 2009. No. 1. Pp. 18-33. (in Russian).

11. Mangler R. "Desiro rus": a promising electric train for commuter traffic in Russia. Lokomotiv-Inform. 2012. No. 10. Pp. 20-24. (in Russian).

12. Bogatyrev B., Moguchev A. EP2D electric train: the future is already here. Transmashholding: Zhurnal dlya Partnerov. 2016. No. 2(6/2016). Pp. 4-11. (in Russian).

13. Ignatov G. S. Interregional two-system electric train. Lokomotiv-Inform. 2012. No. 12. Pp. 16-19. (in Russian).

14. Sobolevskaya M. B., Sirota S. A. Basic concepts of passive safety of high-speed passenger trains at crash collisions. Teh. Meh. 2015. No.1. Pp. 84-96. (in Russian).

15. Naumenko N. Yu., Sobolevska M. B., Khizha I. Yu. Estimation of dynamic loads on a reference train with a passive safety system in its collisions with an identical train and a freight car. Teh. Meh. 2017. No. 3. Pp. 72-83. (in Russian).

https://doi.org/10.15407/itm2017.03.072 